\title{
Toxicity of Corymbia citriodora essential oil compounds against Ascia monuste (Linnaeus, 1764) (Lepidoptera: Pieridae) and Plutella xylostella (Linnaeus, 1758) (Lepidoptera: Plutellidae)
}

\section{Renata C. Santos ${ }^{\circledR}$, Jhersyka S. Paes ${ }^{\circledR}$, Arthur V. Ribeiro ${ }^{\circledR}$, Abraão A. Santos ${ }^{ \pm=}{ }^{\infty}$, Marcelo C. Picanço}

Departamento de Entomologia, Universidade Federal de Viçosa, Viçosa, Minas Gerais, Brazil.

拝=Corresponding author: abraaosantos.entecol@gmail.com

Edited by: Regiane O. Bueno

Received: March 28, 2020. Accepted: July 08, 2020. Published: July 28, 2020.

Abstract. Essential oils (EO's) have been investigated as a safe alternative to pest management. The toxicity of an EO can vary due to abiotic and biotic factors. The individual compounds of different EO's have shown promise to insect control and they may present toxicity similar to or greater than the EO's. In this study, we determined the toxicity of Corymbia citriodora EO compounds against Ascia monuste (Linnaeus, 1764) and Plutella xylostella (Linnaeus, 1758). Citronellal, trans-caryophyllene, and citronellol $\left(\mathrm{LD}_{50}=23.24,24.17\right.$ and $27.84 \mu \mathrm{g} / \mathrm{mg}$, respectively) were the most toxic compounds to $A$. monuste. On the other hand, $\alpha$-pinene and $\beta$-pinene presented low toxicity to this pest. For $P$. xylostella, citronellol and citronellal were the most toxic compounds $\left(\mathrm{LD}_{50}=22.36\right.$ and $25.53 \mu \mathrm{g} / \mathrm{mg}$, respectively). The other compounds presented lower toxicity with similar doses. Thus, the individual compounds of $C$. citriodora EO can be an alternative for $A$. monuste and $P$. xylostella control.

Keywords: botanical insecticide, crop protection, Myrtaceae, terpenes.

Essential oils (EO's) have been extensively studied as a safe alternative to pest management. These substances contain a diversity of compounds with concentrations varying in the EO's due to abiotic and biotic factors such as harvest time (Filomeno et al. 2017) and region of the plant where the material has been collected (Alves et al. 2016). This difference in EO's composition may results in different toxicity among plants of the same species (Alves et al. 2016; Filomeno et al. 2017).

Some studies indicated that the individual compounds from EO's have the potential to control insects, with toxicity similar to or greater than the EO's (Tak et al. 2016). In previous works, we found that Corymbia citriodora (Myrtaceae) EO is promising for the control of Ascia monuste (Linnaeus, 1764) (Lepidoptera: Pieridae) (Ribeiro et al. 2018) and Plutella xylostella (Linnaeus, 1758) (Lepidoptera: Plutellidae) (Filomeno et al. 2017), pests of the brassica crops in temperate and tropical areas. However, changes can occur in the composition of $C$. citriodora EO (e.g., the harvest time), resulting in different insecticidal activity (Filomeno et al. 2017). Thus, the individual compounds of this EO can be an alternative use in pest control. Therefore, we determined the toxicity of $C$. citriodora EO compounds against $A$. monuste and $P$. xylostella.

Larvae of $A$. monuste and $P$. xylostella were obtained from a rearing maintained in the laboratory. Both larvae were fed with leaves of kale and adults with a mixture of honey and water. Bioassays were performed with second-instar larvae of both insect species. The chemical composition of $C$. citriodora essential oil is: citronellal (86.8\%), citronellol (3.3\%), isopulegol (4.7\%), trans-caryophyllene (1.2\%), $\alpha$-pinene $(0.6 \%)$ and $\beta$-pinene $(0.9 \%)$ (Filomeno et al. 2017). Thus, citronellal, citronellol, (-)-isopulegol, trans-caryophyllene, $\alpha$-pinene, and $\beta$-pinene were obtained from Sigma Aldrich and used as received.

In the lethal dose bioassay, we determined the lethal dose of each compound for both species to kill $50 \%$ of population $\left(\operatorname{LD}_{50}\right)$. The treatments consisted of the isolated compounds and acetone $(99.5 \%$, Vetec) as solvent. The doses tested $(\mu \mathrm{g} / \mathrm{mg})$ for $A$. monuste were as follows: citronellal $(10,15,20,25,30,35$, and 40$)$, citronellol $(5,15$, $20,25,30,35$, and 45), (-)-isopulegol (15, 20, 25, 30, 35, and 45), trans- caryophelene $(15,25,35,40,45$, and 50), $\alpha$-pinene $(10,15,20,25$, 30,35 , and 50), and $\beta$-pinene $(10,15,20,25,30,35$, and 50). For $P$. xylostella, we tested: citronellal $(10,20,30,40$, and 50), citronellol $(10,20,40$, and 50), (-)-isopulegol $(10,20,30,40,50$, and 70), transcaryophelene (20, 40, 80, and 90), $\alpha$-pinene $(15,30,40,60$, and 80$)$, and $\beta$-pinene $(20,30,40,60$, and 80 ) The mass of the 30 larvae of each species was obtained using an analytical balance (Gehaka, AG200). Four replicates were used for each tested dose. Each replicate consisted of 10 larvae of $A$. monuste or $P$. xylostella in a Petri dish $(9 \mathrm{~cm}$ of diameter $\times 2 \mathrm{~cm}$ in height) with a leaf disk $(7.5 \mathrm{~cm}$ in diameter) using leaves of kale as food source.

The treatments were applied $(0.5 \mu \mathrm{L} /$ larvae $)$ in the dorsal thorax of larvae using a microsyringe (Hamilton ${ }^{\circledR}, 10 \mu \mathrm{L}$ ). After the application, Petri dishes were placed in an incubator at $25 \pm 2{ }^{\circ} \mathrm{C}$, relative humidity of $75 \pm 5 \%$ and photoperiod of $12 \mathrm{~h}$. The mortality was evaluated after $48 \mathrm{~h}$, and larvae were considered dead when they did not move while touched by a fine brush. Mortality in treatments was corrected to that occurred in the control (acetone) by Abbott formula (Abbott 1925). Data were submitted to Probit analysis (PROC PROBIT SAS) and models with a probability of acceptance of the null hypothesis higher than $5 \%$ $(P>0.05)$ were accepted by the chi-square goodness-of-fit test. The lethal doses and their respective fiducial limits at $95 \%$ probability $\left(\mathrm{FL}_{95}\right)$ were obtained.

The compounds of $C$. citriodora EO were toxic to $A$. monuste and P. xylostella. Citronellal, trans-caryophyllene, and citronellol were the most toxic compounds to A. monuste (Fig. 1). On the other hand, $\alpha$-pinene and $\beta$-pinene showed low toxicity to this pest at the highest tested dose i.e., $50 \mu \mathrm{g}$ of compounds/mg of larvae [(mean $\pm \mathrm{SE}$ ); $\alpha$-pinene $(26.67 \pm 7.07 \%) ; \beta$-pinene $(28.33 \pm 7.03 \%)]$. Thus, the lethal doses of these two compounds were not determined for $A$. monuste. For P. xylostella, citronellal and citronellol were the most toxic compounds (Fig. 2). The other compounds presented lower toxicity with similar doses for this pest. 

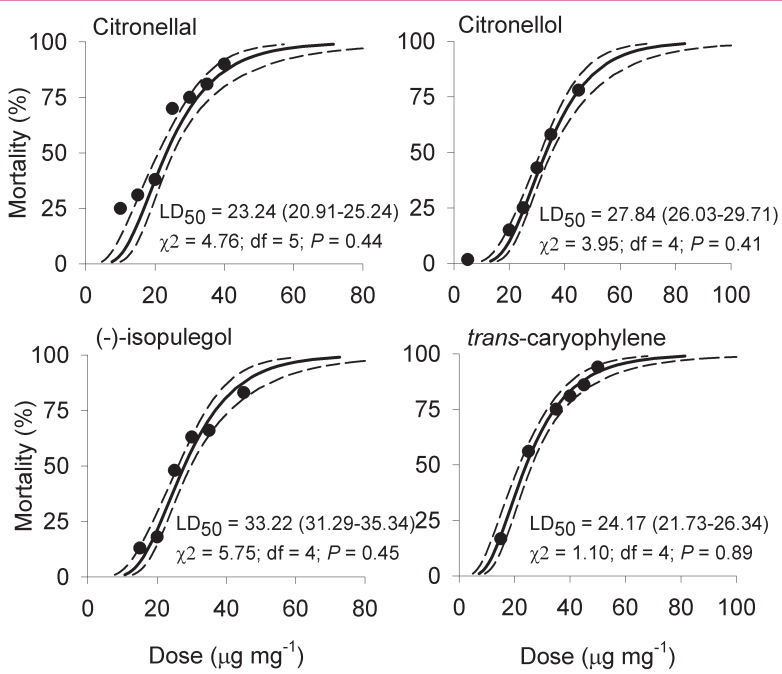

Figure 1 . Toxicity of $C$. citriodora essential oil compounds to $A$. monuste. Solid lines indicate the estimated lethal dose values ( $\mu \mathrm{g}$ of substance/mg of larvae) and dotted lines represent fiducial limits at $95 \%$ of probability. Symbols show the average mortality for each tested dose.
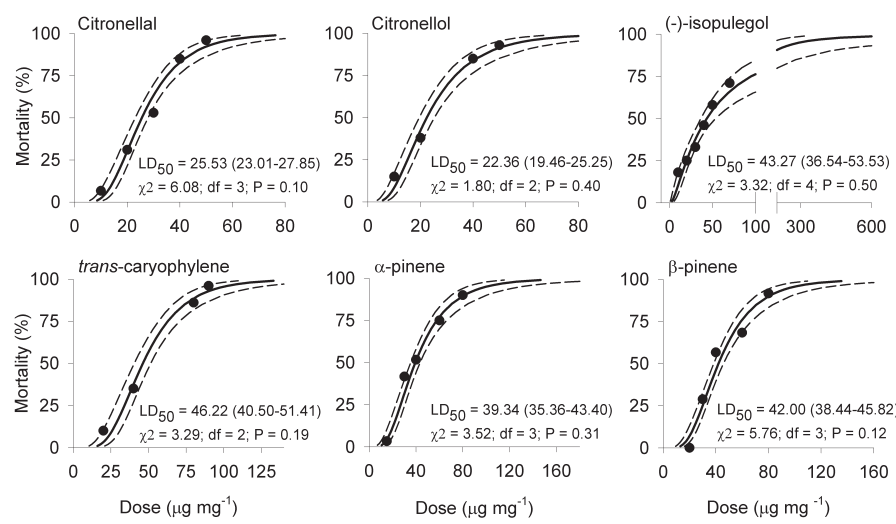

Figure 2. Toxicity of $C$. citriodora essential oil compounds to $P$. xylostella. The solid lines indicate the lethal dose values ( $\mu \mathrm{g}$ of substance per $\mathrm{mg}$ of larvae) estimated and dotted lines represents fiducial limits at $95 \%$ of probability. Symbols show the average mortality for each tested dose.

In general, citronellal and citronellol were the most toxic compounds, i.e., showed the lowest lethal doses for the two species. Citronellal was reported as the most abundant compound in the $C$. citriodora EO and therefore the responsible for this EO insecticidal activity against $A$. monuste and P. xylostella (Filomeno et al. 2017; Ribeiro et al. 2018). However, citronellol exhibited similar toxicity to citronellal against $P$. xylostella. Thus, in addition to the proportion of the compounds in the EO, chemical structure and biological traits such as cuticular penetration perform a role in toxicity (Tong \& Coats 2012; Tak \& Isman 2015, 2017).

A diversity of mode of actions is usually associated to EO compounds such as interference in octopamine activity and in calcium channels, and inhibition of acetylcholinesterase and detoxifying enzymes (e.g., cytochrome P450 monooxygenases) (Priestley et al. 2003; Rattan 2010; Tong \& Coats 2012). Citronellal and citronellol present functional groups with oxygen atoms in their structure. These groups are indicated as responsible for the binding between terpenes and GABA receptors, resulting in a fast insecticide action (Tong \& Coats 2012). This is corroborated by the fact that the lethal times required to kill $50 \%$ of $A$. monuste and $P$. xylostella populations by $C$. citriodora EO were $0.2 \mathrm{~h}$ and $0.52 \mathrm{~min}$, respectively (Filomeno et al. 2017; Ribeiro et al. 2018). This fast action is probably associated with the high proportion of citronellal and citronellol in this EO along with the binding of these compounds to GABA receptors (Tong \& Coats 2012).

As for the other compounds, this variable mode of action could also explain their low toxicity. However, other factors may be associated with the high doses observed in our study such as low cuticular penetration (Tak \& Isman 2015, 2017). Tak \& Isman (2017) suggested that hydrocarbon compounds do not easily penetrate the insect cuticle due to a lack of oxygenation needed for hydrogen bonding. Most of the compounds present in the $C$. citriodora EO do not have oxygen functional groups. Taken together, these points may explain the low toxicity observed.

In conclusion, C. citriodora EO compounds are toxic to both $A$. monuste and $P$. xylostella. Thus, the use of the individual compounds of $C$. citriodora EO is an alternative for the development of new insecticides for both pests.

\section{Acknowledgments}

We thank Dr. Leandro Bacci (Universidade Federal de Sergipe) who provided the compounds used in this study. We are thankful to Jorgiane Parish and Matt Parish (The University of Adelaide - Australia) for the English editing of the text.

\section{Authors' contribution}

AAS and MCP experimental design. RCS and JSP performed the bioassays and analyzed data. AAS and AVR wrote the manuscript. All authors read and approved the final version.

\section{References}

Abbott, W. S. (1925) A method of computing the effectiveness of an insecticide. Journal of Economic Entomology, 18: 265-267. doi: 10.1093/jee/18.2.265a

Alves, M. F.; Nizio, D. A. C.; Sampaio, T. S.; Nascimento-Junior, A. F.; Brito, F. A.; Melo, J. O.; Arrigoni-Blank, M. F.; Gagliardi, P. R.; Machado, S. M. F.; Blank, A. F. (2016) Myrcia lundiana Kiaersk native populations have different essential oil composition and antifungal activity against Lasiodiplodia theobromae. Industrial Crops and Products, 85: 266-273. doi: 10.1016/j.indcrop.2016.03.039

Filomeno, C. A.; Barbosa, L. C. A.; Teixeira, R. R.; Pinheiro, A. L.; Farias, E. S.; Silva, E. M. P.; Picanço, M. C. (2017) Corymbia spp. and Eucalyptus spp. essential oils have insecticidal activity against Plutella xylostella. Industrial Crops and Products, 109: 374-383. doi: 10.1016/j.indcrop.2017.08.033

Priestley, C. M; Williamson, E. M.; Wafford, K. A.; Sattelle, D. B. (2003) Thymol, a constituent of thyme essential oil, is a positive allosteric modulator of human GABA receptors and a homo-oligomeric GABA receptor from Drosophila melanogaster. British Journal of Pharmacology, 140: 1363-1372. doi: 10.1038/sj.bjp.0705542

Rattan, R. S. (2010) Mechanism of action of insecticidal secondary metabolites of plant origin. Crop Protection, 29: 913-920. doi: 10.1016/j.cropro.2010.05.008

Ribeiro, A. V.; Farias, E. S.; Santos, A. A.; Filomeno, C. A.; Santos, I. B.; Barbosa, L. C. A.; Picanço, M. C. (2018) Selection of an essential oil from Corymbia and Eucalyptus plants against Ascia monuste and its selectivity to two non-target organisms. Crop Protection, 110: 207213. doi: 10.1016/j.cropro.2017.08.014

Tak, J. H.; Isman, M. B. (2017) Enhanced cuticular penetration as the mechanism of synergy for the major constituents of thyme essential oil in the cabbage looper, Trichoplusia ni. Industrial Crops and Products, 101: 29-35. doi: 10.1016/j.indcrop.2017.03.003

Tak, J. H.; Isman, M. B. (2015) Enhanced cuticular penetration as the mechanism for synergy of insecticidal constituents of rosemary essential oil in Trichoplusia ni. Scientific Reports, 5: 1-10. doi: $10.1038 /$ srep 12690

Tak, J. H.; Jovel, E.; Isman, M. B. (2016) Comparative and synergistic activity of Rosmarinus officinalis L. essential oil constituents against the larvae and an ovarian cell line of the cabbage looper, Trichoplusia ni (Lepidoptera: Noctuidae). Pest Management Science, 72: 474-480. doi: 10.1002/ps.4010

Tong, F.; Coats, J. R. (2012) Quantitative structure-activity relationships of monoterpenoid binding activities to the housefly GABA receptor. Pest Management Science, 68: 1122-1129. doi: 10.1002/ps.3280 